\title{
Comparison of Newer Disinfectant (Peroxygen Compound) Efficiency against Formaldehyde in Disinfection of Operation Theatres in a Government Tertiary Care Hospital in Tamil Nadu, India
}

\author{
S. Nithya Gomatheswari* \\ Department of Microbiology, Thoothukudi Govt. Medical College, \\ Thoothukudi-628008, Tamil Nadu, India \\ *Corresponding author
}

\begin{tabular}{|c|c|}
\hline & A B S T R A C T \\
\hline & $\begin{array}{l}\text { The aim of this study was to find an alternative chemical disinfectant to formaldehyde and } \\
\text { also to know the efficacy of a newer disinfectant on commonly isolated organisms in the } \\
\text { operation theatre using Air sampler. This study was conducted in the Tirunelveli } \\
\text { Government Medical College Hospital, Tirunelveli for a period of one year. Two operation }\end{array}$ \\
\hline Keywords & theatres were selected except septic theatre. In each operation theatre, after formalin \\
\hline $\begin{array}{l}\text { Formaldehyde, } \\
\text { Operation theatre, Air } \\
\text { sampler, Commercial } \\
\text { disinfectant containing } \\
\text { peroxygen compound. }\end{array}$ & $\begin{array}{l}\text { weeks. Subsequently another commercial disinfectant containing peroxygen compound } \\
\text { was fogged daily and samplings were done using Blood agar air sampler strips. The } \\
\text { growth was identified by colony characteristics, Grams stain and standard biochemical } \\
\text { tests. Efficacy of commercial disinfectant was tested by bactericidal activity on various }\end{array}$ \\
\hline Article Info & $\begin{array}{l}\text { organisms. After fogging with peroxygen compound, the preoperative counts in the } \\
\text { operation theatre were low as compared to post-operative counts. After formaldehyde }\end{array}$ \\
\hline $\begin{array}{l}\text { Accepted: } \\
\text { 24 September } 2017 \\
\text { Available Online: } \\
\text { 10 November } 2017\end{array}$ & $\begin{array}{l}\text { fumigation, the preoperative bacterial counts ranged from } 47 \text { to } 109 \text { cfu whereas after } \\
\text { Commercial disinfectant fogging, the preoperative bacterial counts ranged from } 9 \text { to } 18 \mathrm{cfu} \\
\text { at } 1 \text { feet and } 6 \text { feet. After formalin fumigation, the organisms isolated were Acinetobacter } \\
\text { baumanii, Coagulase Negative Staphylococcus sp, Methicillin sensitive Staphylococcus }\end{array}$ \\
\hline & $\begin{array}{l}\text { aureus and Micrococci. Bacillus spand Micrococci were isolated following Peroxygen } \\
\text { fogging. The bactericidal activity of peroxygen disinfectant was effective at } 1 \% \\
\text { concentration for } 10 \text { minutes against the commonly isolated organisms. }\end{array}$ \\
\hline
\end{tabular}

\section{Introduction}

Disinfection is a process that eliminates most of the pathogenic microorganisms, except bacterial spores (Mackie and McCartney Practical Medical Microbiology, 1996). They are broadly classified as: alcohols, aldehydes (such as formaldehyde, glutaraldehyde, orthophthalaldehyde), oxidizing agents (such as chlorine and chlorine releasing compounds), hydrogen peroxide, peracetic acid, phenolic and quaternary ammonium compounds (Sterilisation, Disinfection and cleaning of equipments, MAC manual, 2007). Nosocomial infections have been reported due to usage of contaminated antiseptic solutions which can grow pathogenic organisms like Pseudomonas aeruginosa and Klebsiella species (Arjun wadkar et al., 2001). The disinfectants used in the hospitals should be 
freshly prepared and should be of adequate strength. Formalin is commercially available as $40 \%$ solution of formaldehyde in water. When formalin is heated, formaldehyde vapor is generated. Formaldehyde fumigation has been accepted method of disinfection for operation theatres (OT) and critical care units in developing countries because of its cost effective nature. Due to their potential carcinogenic and irritant nature, we may opt for other agents such as hydrogen peroxide, hydrogen peroxide with silver nitrate, peracetic acid and other like quaternary ammonium compounds. Most effective method to prevent exposure to formaldehyde is to substitute a safer, less toxic highly penetrating disinfectant. In this study we chose a newer commercial disinfectant peroxygen compound as an alternative because it has nontoxic and non-corrosive property. The reentry into the OT will be by $40 \mathrm{~min}$ where as in case of formaldehyde it needs to be closed for $24 \mathrm{hrs}$ followed by neutralization with ammonia. In case of hydrogen peroxide, the reentry into the OT is in 1 hour but it is highly corrosive.

In many situations, patients may stay for a brief period in the operation theatre and it's environment plays a major role in the onset of infection because of multifactorial cause of infection (Mangram et al., 1999). The bacterial count in operation theatre is influenced by the Type of surgery, Quality of air provided, Rate of air exchange, Number of persons present in the theatre, Movement of operation room personnel, Level of compliance with infection control practices and efficiency of the sterilization agents (Ayliffe et al., 1991) (Dharan and Pittet, 2002) (Guidelines, CDC Atlanta, 2003). Microbial contamination in an OT has continued to increase nosocomial infection. Infections acquired in the OT are often caused by resistant bacteria which pose a significant threat to patients.
Surgical site infections are the second most common healthcare associated infection, accounting for $17 \%$ of all HAIs among hospitalized patients (Klevens et al., 2008). In deep or extensive wound infection this results in a mortality rate of $70-80 \%$ (Altemeier, 1982).Air sampler calculates suspended particles whereas settle plate calculates the settling large bacteria carrying particles (Landrin et al., 2005). But it may be ideal to survey the operation theatre for anaerobes in situations when newly constructed, any remodeling or structural alterations are done. The microbiological quality of theatre air is one of the significant parameter for controlling surgical wound infections (Fleischer et al., 2005) (Mangram et al., 1999). This study was carried out to find an alternative chemical disinfectant to formalin and its influence on commonly isolated organisms in the operation theatre.

The main objectives of this study to check efficiency of a commercial disinfectant that contains oxone (potassium peroxymonosulphate, sodium dodecylbenzenesulfonate, and inorganic buffers) against formaldehyde by air sampling method. And also to study the types of microorganisms isolated in the operating room environment. Finally, to study the efficacy of the disinfectant (peroxygen compound) against commonly isolated organisms.

\section{Materials and Methods}

The study was conducted in conventional operation theatres at Tirunelveli Medical College Hospital after obtaining Ethical clearance from Institutional Ethical Committee.

Study period -1 year

Type of study - Epidemiological investigation 
Inclusion criteria - Operation theatre where emergency surgeries (OT 1) and elective surgeries (OT 2) are conducted.

Exclusion criteria - Septic operation theatres

In each operation theatre, after formalin fumigation, sampling was done for six days from Monday to Saturday for a period of 4 weeks.

Subsequently another commercial disinfectant containing peroxygen compound was fogged daily.

Using Blood agar air sampler strips sampling was done (Landrin et al., 2005). The growth was identified by colony characteristics, Grams stain and standard biochemical tests described in Bailey and Scott's Diagnostic Microbiology and Mackie and McCartney, Practical Medical Microbiology. Antibiotic sensitivity testing of isolates was performed by Modified Kirby Bauer Method as per CLSI guidelines.

\section{Fumigation with formaldehyde}

Electric Boiler Fumigation Method: For each 1000 cubic feet, $500 \mathrm{ml}$ of formaldehyde (40\% solution) added in $1000 \mathrm{ml}$ of tap water in an electric boiler. All the doors were sealed and switched on. Calculation of the operation room size in cubic feet $(\mathrm{L} \times \mathrm{B} \times \mathrm{H})$ and the required amount of formaldehyde is calculated. Formaldehyde required for fumigation $=500 \mathrm{ml}$ for 1000 cubic feet . Ammonia required for neutralization $=300$ $\mathrm{ml}$ of $10 \%$ ammonia for $500 \mathrm{ml}$ of formaldehyde.

\section{Fogging with commercial disinfectant (Peroxygen compound)}

As per the manufacturers' instruction, using the fogging machine, the operation theatre is disinfected every morning and other areas like floors, walls, equipments, operation tables and O.T lamp etc. are mopped. Microbiological monitoring was done by air sampling method to know the effectiveness of the disinfectant before the start of the surgery.

\section{Air sampler}

This study was planned with a Hi-media Air sampler device at different areas of Operation Theatre (A/C, 6 feet height and 1 feet height (above the O.T table). The head of the Air sampler is autoclaved every time before sampling. The air sample was drawn into the sampling head by means of an impeller (Figure 1). The impeller then directs the air onto an agar strip fitted around the circumference of the sampling head. The viable microbes which grow into colonies in the strip media (Blood agar) was counted and calculated for $\mathrm{m}^{3}$.

As recommended by the manufacturer, blood agar strips in Reuter's centrifugal sampler, operating on impaction principle (Bailey and Scott's Diagnostic Microbiology, 1994) was used to collect air samples for 8 minutes at different areas of OT $(\mathrm{A} / \mathrm{C}, 6 \mathrm{ft}$ height and 1 feet height above the OT table). They were incubated at $37^{\circ} \mathrm{C}$ for 24 hours and the colony forming units (cfu) were counted followed by identification of bacteria (Figure 2). Microorganisms were identified through Gram stain and biochemical methods (Mackie and McCartney Practical Medical Microbiology, 1996). Colonies were counted based on the recommendations, $\mathrm{cfu} / \mathrm{m}^{3}=$ No. of colonies on agar strip $\times 25 /$ Sampling time in minutes. The acceptable upper limit is 180 cfu $/ \mathrm{m}^{3}$ which approximately corresponds to 10 colonies settling on a plate (Kelkar et al., 2003).

\section{To Test the efficacy of disinfectant (Peroxygen compound)}

The efficacy of disinfectant was tested by a simplified bactericidal activity. Aliquots of disinfectant solution were prepared by adding 
250 micro liters of a $4 \%$ and $2 \%$ solution of Peroxygen compound in distilled water to 750 micro liters of peptone water to obtain a final concentration of $1 \%$ and $0.5 \%$.About 200 microlitres of each prepared culture was added to each of the $1 \%$ and $0.5 \%$ aliquots of disinfectant and incubated. Samples were plated after 10 minutes, 30 minutes and 60 minutes. Aliquots of peptone water and distilled water mixed in the same proportion (750 microlitres and 250 microlitres respectively) were inoculated with cultures to serve as controls. This was tested for microbicidal activity against common isolates like Staphylococcus aureus, Escherichia coli, Klebsiella pneumoniae, Proteus vulgaris, Acinetobacter sp, Enterobacter sp, Citrobacter koseri, Salmonella typhi and Candida albicans. ATCC control strains of E. coli 25922, Klebsiella pneumoniae 700603, Staphylococcus aureus 25923, Pseudomonas aeruginosa 27853 were obtained from JIPMER, Pondicherry. Results were expressed as 'growth' (+) or 'no growth' (-).

\section{Results and Discussion}

\section{Formalin fumigation (Table 1 and 2)}

\section{OT 1}

The preoperative count ranges from 84 to 178 cfu at 1 feet ht and 47 to 131 cfu at 6 feet ht and the post-operative bacterial count ranges from 112 to $170 \mathrm{cfu}$ at 1 feet ht and 98 to140 at 6 feet ht.

\section{OT 2}

The preoperative count ranges from 71 to 156 cfu at 1 feet ht and 109 to $184 \mathrm{cfu}$ at 6 feet ht and the post-operative bacterial count ranges from 146 to $174 \mathrm{cfu}$ at 1 feet ht and 131 to $225 \mathrm{cfu}$ at 6 feet ht. The above result explains that preoperative and post-operative counts were within acceptable limit in both operation theatres. After formaldehyde fumigation, the preoperative bacterial counts ranged from 47 to $109 \mathrm{cfu}$ at 1 feet and 6 feet.

\section{Commercial disinfectant fogging (Table 1} and 2)

\section{OT 1}

Bacterial counts ranges from 11 to $37 \mathrm{cfu}$ at 1 feet ht and 11 to $45 \mathrm{cfu}$ at 6 feet ht before the surgery and the counts after completion of all surgeries ranges from 59 to $162 \mathrm{cfu}$ at 1 feet ht and 26 to $130 \mathrm{cfu}$ at 6 feet ht.

\section{OT 2}

Bacterial count ranges from 18 to $65 \mathrm{cfu}$ at 1 feet ht and 9 to $88 \mathrm{cfu}$ at 6 feet ht before the surgery whereas counts after the end of all surgeries ranges from 56 to $146 \mathrm{cfu}$ at 1 feet ht and 28 to $100 \mathrm{cfu}$ at 6 feet ht.

The above results conclude that bacterial counts before the surgery and after the end of all surgeries were within the acceptable limit in both operation theatres. After Commercial disinfectant fogging, the preoperative bacterial counts ranged from 9 to $18 \mathrm{cfu}$ at 1 feet and 6 feet.

\section{Organisms isolated and their Antibiotic sensitivity pattern}

\section{Formalin fumigation}

The organisms isolated were Acinetobacter baumanii, Coagulase Negative Staphylococcus, Methicillin sensitive Staphylococcus aureus and Micrococci.

Coagulase Negative Staphylococcus (CONS) was sensitive to amikacin, Vancomycin, cefoxitin, intermediate sensitive to cloxacillin and resistant to erythromycin, ampicillin. Acinetobacter baumanii were sensitive to Amikacin and Imipenem, intermediate sensitive to ciprofloxacin, ceftazidime and 
resistant to piperacillin-tazobactum and third generation Cephalosporins. Staphylococcus aureus isolated were all sensitive to
Cloxacillin, Amikacin, Vancomycin and cefoxitin and resistant to cephalexin, erythromycin.

Table.1 OT 1 Air sampling

\begin{tabular}{|c|c|c|c|c|c|c|c|c|c|}
\hline \multirow[t]{3}{*}{ Areas } & \multirow[t]{3}{*}{ Days } & \multicolumn{4}{|c|}{ Formalin } & \multicolumn{4}{|c|}{ Peroxygen compound } \\
\hline & & \multicolumn{2}{|c|}{ No. of colonies } & \multicolumn{2}{|c|}{ CFU/m3 } & \multicolumn{2}{|c|}{ No. of colonies } & \multicolumn{2}{|c|}{ CFU/m3 } \\
\hline & & Before & After & Before & After & Before & After & Before & After \\
\hline $\mathrm{A} / \mathrm{C}^{*}$ & Day 1 & 69 & 43 & 215 & 134 & 45 & 11 & 140 & 34 \\
\hline $6 \mathrm{ft} \mathrm{ht}$ & & 15 & 32 & 47 & 110 & 8 & 34 & 25 & 106 \\
\hline $1 \mathrm{ft} \#$ & & 27 & 38 & 84 & 112 & 9 & 44 & 28 & 137 \\
\hline $\mathrm{A} / \mathrm{C}$ & Day 2 & 45 & 32 & 141 & 109 & 13 & 9 & 41 & 28 \\
\hline $6 \mathrm{ft} \mathrm{ht}$ & & 37 & 46 & 116 & 143 & 13 & 42 & 41 & 130 \\
\hline $1 \mathrm{ft}$ & & 42 & 51 & 130 & 159 & 10 & 52 & 31 & 162 \\
\hline $\mathrm{A} / \mathrm{C}$ & Day 3 & 44 & 36 & 139 & 111 & 25 & 17 & 78 & 53 \\
\hline $6 \mathrm{ft} \mathrm{ht}$ & & 40 & 47 & 126 & 146 & 9 & 25 & 28 & 78 \\
\hline $1 \mathrm{ft}$ & & 58 & 65 & 181 & 203 & 12 & 33 & 37 & 103 \\
\hline $\mathrm{A} / \mathrm{C}$ & Day 4 & 73 & 61 & 228 & 190 & 32 & 28 & 100 & 88 \\
\hline $6 \mathrm{ft} \mathrm{ht}$ & & 39 & 46 & 123 & 143 & 14 & 8 & 45 & 26 \\
\hline $1 \mathrm{ft}$ & & 49 & 53 & 150 & 165 & 6 & 19 & 19 & 59 \\
\hline $\mathrm{A} / \mathrm{C}$ & Day 5 & 86 & 82 & 269 & 256 & 27 & 19 & 84 & 59 \\
\hline $6 \mathrm{ft} \mathrm{ht}$ & & 31 & 42 & 131 & 98 & 9 & 11 & 28 & 114 \\
\hline $1 \mathrm{ft}$ & & 42 & 51 & 130 & 159 & 4 & 42 & 11 & 130 \\
\hline $\mathrm{A} / \mathrm{C}$ & Day 6 & 79 & 60 & 247 & 186 & 37 & 22 & 116 & 69 \\
\hline $6 \mathrm{ft} \mathrm{ht}$ & & 32 & 46 & 100 & 143 & 4 & 17 & 11 & 54 \\
\hline $1 \mathrm{ft}$ & & 41 & 59 & 128 & 154 & 6 & 26 & 19 & 81 \\
\hline
\end{tabular}

*Bacterial air counts from the $\mathrm{A} / \mathrm{C}$ inlet were higher in the morning than in the evenings, this was probably due to settling of particles in compartment of $\mathrm{A} / \mathrm{C}$.

\# Counts (1 ft above the OT table) were less in the morning as compared to evening, this shows that air counts were influenced by human activities inside the operation theatre. 
Table.2 OT 2 Air sampling

\begin{tabular}{|c|c|c|c|c|c|c|c|c|c|}
\hline \multirow[t]{3}{*}{ Areas } & \multirow[t]{3}{*}{ Days } & \multicolumn{4}{|c|}{ Formalin } & \multicolumn{4}{|c|}{ Peroxygen compound } \\
\hline & & \multicolumn{2}{|c|}{ No. of colonies } & \multicolumn{2}{|c|}{ CFU/m3 } & \multicolumn{2}{|c|}{ No. of colonies } & \multicolumn{2}{|c|}{ CFU/m3 } \\
\hline & & Before & After & Before & After & Before & After & Before & After \\
\hline $\mathrm{A} / \mathrm{C}^{*}$ & Day 1 & 55 & 45 & 171 & 141 & 30 & 11 & 93 & 34 \\
\hline $6 \mathrm{ft} \mathrm{ht}$ & & 35 & 44 & 109 & 138 & 3 & 9 & 9 & 28 \\
\hline $1 \mathrm{ft} \#$ & & 23 & 52 & 71 & 162 & 6 & 30 & 18 & 93 \\
\hline $\mathrm{A} / \mathrm{C}$ & Day 2 & 65 & 42 & 203 & 131 & 19 & 14 & 59 & 43 \\
\hline $6 \mathrm{ft} \mathrm{ht}$ & & 37 & 42 & 115 & 131 & 4 & 16 & 13 & 50 \\
\hline $1 \mathrm{ft}$ & & 50 & 47 & 156 & 146 & 9 & 18 & 28 & 56 \\
\hline $\mathrm{A} / \mathrm{C}$ & Day 3 & 66 & 36 & 207 & 111 & 28 & 12 & 88 & 36 \\
\hline $6 \mathrm{ft} \mathrm{ht}$ & & 47 & 58 & 146 & 181 & 5 & 32 & 16 & 100 \\
\hline $1 \mathrm{ft}$ & & 36 & 66 & 113 & 207 & 6 & 47 & 18 & 146 \\
\hline $\mathrm{A} / \mathrm{C}$ & Day 4 & 59 & 47 & 184 & 146 & 45 & 10 & 141 & 32 \\
\hline $6 \mathrm{ft} \mathrm{ht}$ & & 53 & 71 & 165 & 221 & 28 & 18 & 88 & 55 \\
\hline $1 \mathrm{ft}$ & & 28 & 54 & 87 & 168 & 17 & 33 & 53 & 103 \\
\hline $\mathrm{A} / \mathrm{C}$ & Day 5 & 69 & 52 & 215 & 163 & 40 & 11 & 125 & 35 \\
\hline $6 \mathrm{ft} \mathrm{ht}$ & & 59 & 64 & 184 & 202 & 11 & 16 & 34 & $\mathbf{5 0}$ \\
\hline $1 \mathrm{ft}$ & & 42 & 60 & 131 & 186 & 7 & 40 & 20 & 125 \\
\hline $\mathrm{A} / \mathrm{C}$ & Day 6 & 54 & 47 & 168 & 146 & 35 & 13 & 109 & 41 \\
\hline $6 \mathrm{ft} \mathrm{ht}$ & & 45 & 72 & 141 & 225 & 15 & 25 & 48 & 78 \\
\hline $1 \mathrm{ft}$ & & 39 & 65 & 121 & 206 & 21 & 37 & 65 & 115 \\
\hline
\end{tabular}

Table. 3 The bactericidal activity of $0.5 \%$ and $1 \%$ peroxygen compound disinfectant among commonly isolated organisms

\begin{tabular}{|c|c|c|c|c|c|c|c|}
\hline \multirow{4}{*}{ Organisms } & \multicolumn{7}{|c|}{ Growth at indicated exposure concentration and time } \\
\hline & \multicolumn{7}{|c|}{ Test organisms } \\
\hline & Control & & $0.5 \%$ & & & $1 \%$ & \\
\hline & & $10 \mathrm{~min}$ & $30 \mathrm{~min}$ & $60 \mathrm{~min}$ & $10 \mathrm{~min}$ & $30 \operatorname{minn}$ & $60 \mathrm{~min}$ \\
\hline E. coli & + & - & - & - & - & - & - \\
\hline Klebsiella pneumoniae & + & - & - & - & - & - & - \\
\hline Enterobacter aerogenes & + & - & - & - & - & - & - \\
\hline Citrobacter koseri & + & - & - & - & - & - & - \\
\hline Proteus vulgaris & + & + & - & - & - & - & - \\
\hline Staphylococcus aureus & + & - & - & - & - & - & - \\
\hline Staphylococcus epidermidis & + & - & - & - & - & - & - \\
\hline Pseudomonas aeruginosa & + & - & - & - & - & - & - \\
\hline Acinetobacter baumanii & + & + & - & - & - & - & - \\
\hline
\end{tabular}

It was inferred from that the bactericidal activity of $1 \%$ concentration of peroxygen compound is effective at 10 minutes against the commonly isolated organisms. + indicates Growth. - indicates No growth. 
Fig.1 Air sampler

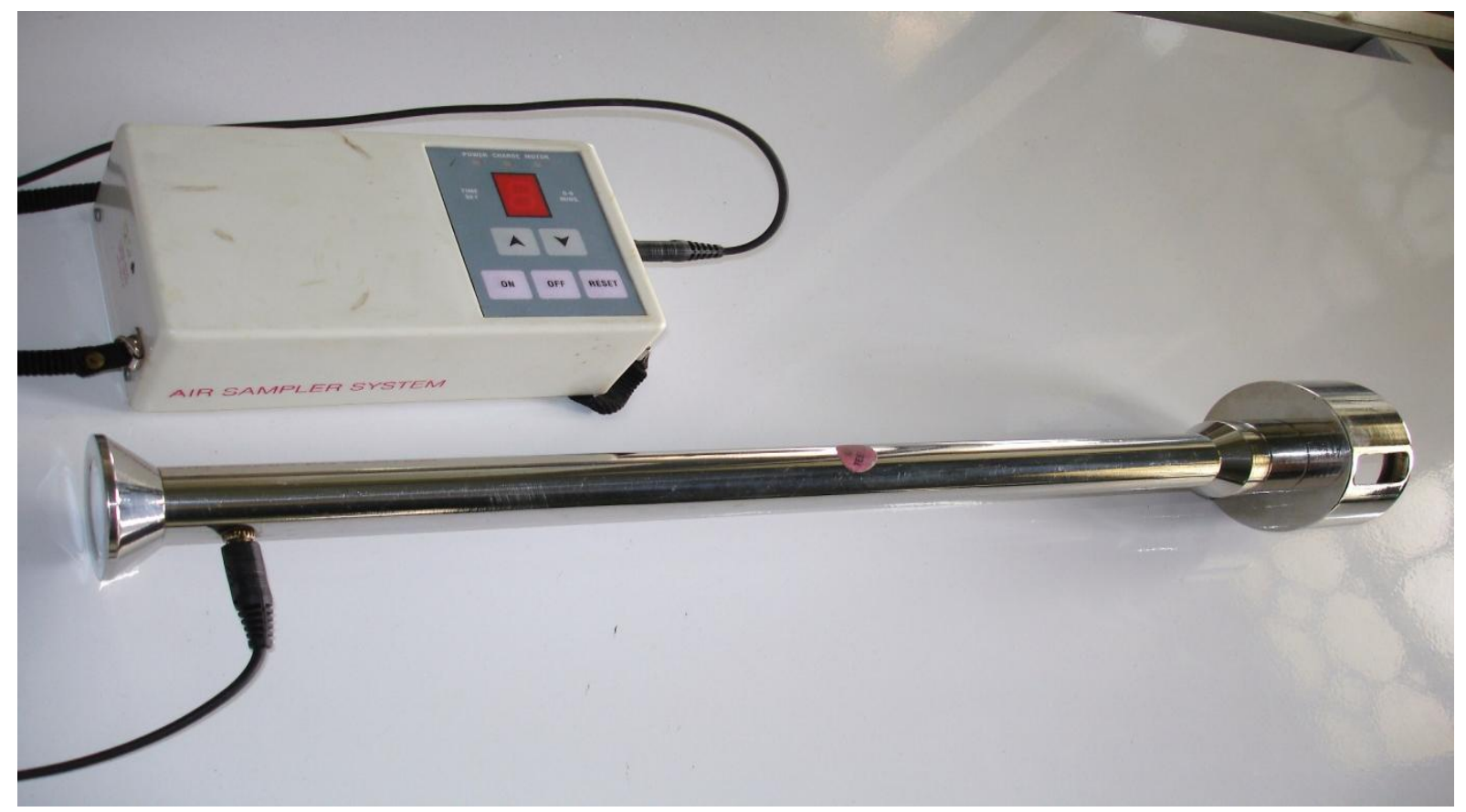

Fig.2 Air sampler strip with growth

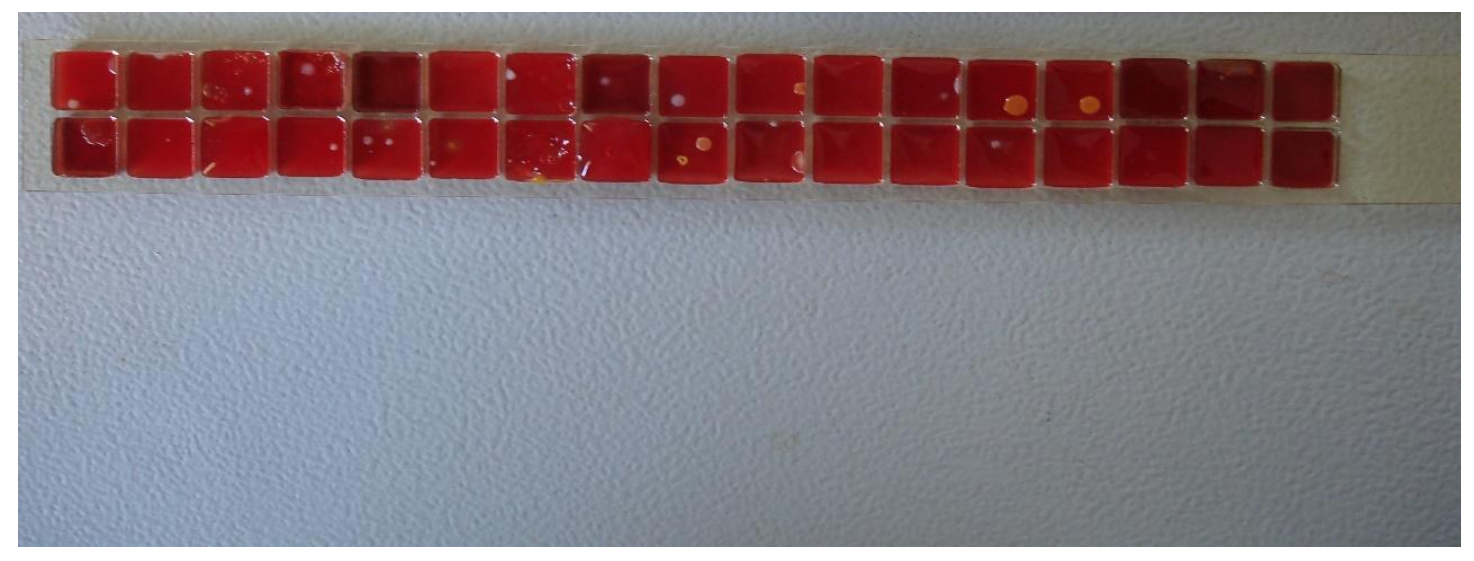

\section{Commercial disinfectant fogging}

In both the Operation theatres, organisms isolated were Micrococci, Bacillus sp at 1 feet height from OT table (OTT) and at 6 feet height.

\section{Efficacy of disinfectant}

The commercial disinfectant containing per oxygen compound was tested for bactericidal activity against common isolates like Staphylococcus aureus, Escherichia coli, Klebsiella pneumoniae, Proteus vulgaris, Acinetobacter baumanii, Enterobacter aerogenes, Citrobacter koseri, Salmonella typhi, Pseudomonas aeruginosa. It was observed that the microbicidal activity of Proteus vulgaris, Acinetobacter baumanii was seen in $30 \mathrm{~min}$ and $60 \mathrm{~min}$ respectively at $0.5 \%$ but its action was good at $1 \%$ in $10 \mathrm{~min}$, other organisms like Staphylococcus aureus, 
Salmonella typhi, Escherichia coli, Klebsiella pneumoniae, Enterobacter aerogenes, Citrobacter koseri, Pseudomonas aeruginosa microbicidal activity was seen in $10 \mathrm{~min}$ in $1 \%$. There was growth in all the control cultures at $1 \%$ and $0.5 \%$ concentration.(Table $3)$.

The OT1 colony forming unit was higher than OT 2 cfu (Table 1 and 2) which may be due to human activity that significantly increases the bacterial count and reaches the peak at the end of the day in both the OTs and was established by Pasquarella et al., (2004) and Ekhaise et al., (2008). The colony forming unit after the use of peroxygen product was always less when compared to formalin indicating its efficacy. In the emergency OT (OT1), cfu were higher as compared to elective operation theatre (OT 2).

By air sampler whether it is formalin or the commercial product, the colony forming units at 1 feet height and above the OTT were within limit.

Counting microbes in the air is not an easy task, but through air and surface sampling it is possible to evaluate bacterial contamination of environment (Davis et al., 1999).

In our study, bacterial count of air is in a range from 9 to $171 \mathrm{CFU} / \mathrm{m} 3$.This is in contradiction to surveillance study at Lahore (Javed et al., 2008) have reported a significantly higher bacterial air count in the range of $6500-15730 \mathrm{CFU} / \mathrm{m}^{3}$.

This wide variation may be attributed the surveillance method used, time of sampling disinfectant used and mechanical ventilation of OTs. It was observed that counts in the range of $700-1800 / \mathrm{m} 3$ were related to significant risk of infection and the risk was slight when they were below 180/m3 (Parker et al., 1978).
Human activity and related factors have more influence on colony forming unit, whether it is measured by settle plate or air sampler (Fleischer et al., 2005). It is evident that there is increase of colony forming unit comparing preoperative and post-operative counts from day 1-6 (Table 1 and 2). The microbicidal activity of the peroxygen compound against common isolates was good at $1 \%$ concentration within 10 minutes (Table 3). Hence, such products with proven efficacy may be used as an alternative to formalin. The environments in the OTs are dynamic and subject to continuous change.

The preoperative bacterial counts were within acceptable limits in both formaldehyde and peroxygen compound but the colony forming units after peroxygen compound fogging were significantly less as compare to formaldehyde The bacterial counts increased after the end of all surgeries than before the start of surgeries by air sampling method after fumigating with formalin and the peroxygen compound in all the operation theatres. Organisms most commonly detected in the Operation theatres were Acinetobacter baumanii, Methicillin sensitive Staphylococcus aureus, Coagulase Negative Staphylococcus sp, Micrococci and Bacillus sp. The bactericidal activity of $1 \%$ concentration was effective at 10 minutes against the commonly isolated organisms.

Newer less toxic disinfecting agents are alternative to formalin and may be used at short intervals for better outcome. Since human activity plays a major role in microbial air quality, meticulous cleaning, thorough washing and strict adherence to operation theatre protocol are essential.

The extra cost spent on this is worth considering the long term impact of formalin, an irritant, toxic, corrosive, and carcinogenic chemical and fogging cannot replace manual cleaning. 


\section{References}

Altemeier, W.A. Sepsis in surgery. Archives of Surgery. 1982;117:107-112.

Arjun wadkar VP, Bal AM, Joshi SA, Kagal AS, Bharadwaj RS. Contaminated antiseptics- an unnecessary hospital hazard. Indian J Med Sci 2001;55:393-8.

Ayliffe GAJ. Role of the environment of the operating suite in surgical wound infection. Rev Infect Dis 1991;13 Suppl 10:S800-4.

Bailey and Scott's Diagnostic Microbiology, 1994; 9th edition:505-523.

Davis, N., Curry, A., Gambhir, A. K., Panigrahi, H., Walker, C. R., Wilkins, E. G., Worsley, M. A. and Kay, P. R. 1999.Intraoperative bacterial contamination in operations for joint replacement. J Bone Joint Surg Br, 81B:8869.

Dharan S and Pittet D. Infection control programme, Department of Internal Medicine, University of Geneva Hospitals, 1211 Geneva 14, Switzerland Environmental controls in operating theatres Available online 29 June 2002.

Ekhaise FO, IghoseweOU, and Ajakpovi OD. Hospital indoor airborne microflora in private and government owned hospitals in Benin City, Nigeria. World $\mathrm{J}$ of Medical Sciences.2008;3(1):19-23.

Fleischer M, Bober,Gheek B, Bortkiewicz O and Rusiecka,Ziolkowska J (2005).Microbiological Control Of Airborne Contamination In Hospitals. Indoor and Built Environment 15153 6.

Guidelines on environmental monitoring for aseptic dispensing facilities - A working group of the Scottish quality assurance specialist interest group - 2002; 3rd edn:2-7.

Guidelines for environmental infection control in health-care facilities recommendations of $\mathrm{CDC}$ and the healthcare infection control practices advisory committee (HICPAC) - US Department of Health and Human Services Centers for Disease Control and Prevention (CDC) Atlanta.2003; 107-108.

Javed, I., Hafeez, R., Zubair, M., Anwar, M. S., Tayyib, M.and Hashain, S. Microbiological surveillance of operation theater and ICU'S of a tertiary care hospital, Lahore. Biomedica 2008; 24:99-102.

Kelkar U, Kelkar S, Bal AM, Kulkarni S, Kulkarni S. Microbiological evaluation of various parameters in ophthalmic operating rooms. The need to establish guidelines. Indian $\mathrm{J}$ Ophthalmol 2003;51:171-6.

Klevens RM, Edwards JR, et al., Estimating health care-associated infections and deaths in U.S. hospitals,2002. Public Health Reports 2007;122:160-166.

Laboratory evaluation of disinfectant for antibacterial efficacy tested by Apollo hospitals, Chennai.

Landrin A, Bissery A, Kac G. Monitoring air sampling in operating theatres: can particle counting replace microbiological sampling? J of Hospital Infection 2005;61(1):27-9

Mackie and McCartney Practical Medical Microbiology,1996: 14 th edition

Mangram,AJ, Horan TC. Pearson ML,etal. Guideline for Prevention of Surgical Site Infection, 1999. The Hospital Infection Control Practices Advisory Committee. Infect Control Hosp Epidemiol1999;20: 250-78.

Manual of Himedia Air sampler system Mark II LA637.

Parker, M. T. In Hospital Associated Infections, Guidelines to laboratory methods. WHO, Regional Office for Europe, Copenhagen. 1978; 28-32.

Pasquarella, C., Masia, M. D. N., nanga, N., Sansebastiano, G.E., Savino, A., 
Signorelli, C. and Veronesi, L. Microbial air monitoring in operating theater: active and passive sampling. Ann Ig. 2004; 16(1-2): 375-86.

Sterilisation, Disinfection and Cleaning of Medical Equipment: Guidance on Decontamination from the Microbiology Advisory Committee to the Department of Health (The MAC Manual) [online]. 2006 [cited 2007 August 10].

Wijesinghe LP and T.K. Weerasinghe. A Study on the Bactericidal Efficiency of Selected Chemical Disinfectants and Antiseptics. Open university Srilanka Journal 2010; 6(0): 44-58.

\section{How to cite this article:}

Nithya Gomatheswari, S. 2017. Comparison of Newer Disinfectant (Peroxygen compound) Efficiency against Formaldehyde in Disinfection of Operation Theatres in a Government Tertiary Care Hospital in Tamil Nadu. Int.J.Curr.Microbiol.App.Sci. 6(11): 3081-3090. doi: https://doi.org/10.20546/ijcmas.2017.611.361 